\title{
EVALUATION OF ANTIOXIDANT AND FREE RADICAL SCAVENGING ACTIVITIES OF DIFFERENT SOLVENT EXTRACTS OF LEAVES OF PIPER UMBELLATUM
}

\section{SETHUPANDIAN GEETHA, KOKKAIAH IRULANDI, PALANICHAMY MEHALINGAM*}

Department of Botany, V. H. N. Senthikumara Nadar College, Virudhunagar, Tamil Nadu, India. Email: mehalingamp@yahoo.co.in Received: 07 October 2016, Revised and Accepted: 25 October 2016

\begin{abstract}
Objective: This study was designed to determine the total phenol, flavonoid content, antioxidant, and free radical scavenging properties of different solvent extracts of Piper umbellatum.
\end{abstract}

Methods: Different solvent extracts evaluated with 1, 1-diphenyl-2-picrylhydrazyl radical scavenging activity and reducing power activity.

Results: The presence of phenol and flavonoid showed highly in the methanol extracts than ethyl acetate and acetone extracts. All the extracts have various level of antioxidant activity. Methanol solvent extract has good extraction and shows significant antioxidant activity. The effect of reducing the power of methanol extract found good antioxidant activity compared with other tested solvent extracts.

Conclusion: On the basis of the above results, we concluded that methanol extract of P. umbellatum whole plant extracts shows a significant antioxidant activity than ethyl acetate and acetone extracts.

Keywords: Piper umbellatum, Antioxidant, 1, 1-diphenyl-2-picrylhydrazyl, Ferric reducing antioxidant power assay, Polar, Nonpolar solvents.

(C) 2017 The Authors. Published by Innovare Academic Sciences Pvt Ltd. This is an open access article under the CC BY license (http://creativecommons. org/licenses/by/4. 0/) DOI: http://dx.doi.org/10.22159/ajpcr.2017.v10i2.15570

\section{INTRODUCTION}

Free radical is the primary harmful health factor in the human systems, when the oxidative molecule formation the loss of electron from one atom due to the oxidative process. Free radical formation is the long chain reaction. Free radical formation due to environmental pollutants, radiation, chemicals and toxins, deep fried, and spicy foods as well as physical stress and depletion of immune system of the human body [1-3]. The oxidative reaction is the crucial role to formation human disorders. They are cancer, emphysema, cirrhosis, atherosclerosis, and arthritis all are correlated with oxidative damage [4]. Free radical formation controlled by such artificial and plant derivate compounds such as vitamin A, C, beta-carotene, and polyphenolic compounds. Phenolic group of compounds possesses the good and properties and used to various diseases.

Piper umbellatum belongs to the family Piperaceae. P. umbellatum originated from tropical America but is now found in tropical rain forest in Africa, Japan, and the Indian Ocean Islands [5]. The genus Piper comprises about 1000-2000 species of shrubs, herbs, and lianas that have economic and ecological values of which P. Umbellatum and Piper guineense [6]. The important phytoconstituents isolated from leaves of $P$. umbellatum $L$. revealed three pure compounds were isoasarone, 2-(4'-methoxyphenyl)-3-methyl-5propenylbenzofuran, and 2,3-dihydro-2-(4-hydrophenyl)-3- methyl-5propenylbenzofuran [7]. The aim of this study was to determine for the first time, comparison of phytochemical analysis and antioxidant activity of three different solvent extracts of $P$. umbellatum leaves. Spectroscopic analysis was determined of the total phenol and total flavonoid content from the leaves extract. Furthermore, total antioxidant activity value was quantified by the ascorbic acid equivalents. Free radical scavenging activity was also determined using 1, 1-diphenyl-2-picrylhydrazyl (DPPH) assay compared to ascorbic acid. Since this plant is used to cure various therapeutic purposes by indigenous people, we have chosen this plant for our investigation.

\section{METHODS}

\section{Plant material}

Leaves samples of P. umbellatum plants were collected from Courtallam hills, Tirunelveli District, Tamil Nadu, India, during the month of October 2015. The plant was identified, and the herbarium specimen was prepared and deposited at Botany Research Laboratory, V.H.N.S.N. College (Autonomous) for future references.

\section{Preparation of leaves extracts}

The fresh leaves were air dried under the fan, and the leaves extracts were prepared by sequential extraction method using three organic solvents on the basis of the polarity of solvents (acetone, ethyl acetate, and methanol). $30 \mathrm{~g}$ of the dry leaves sample was taken in a conical flask and $200 \mathrm{ml}$ of acetone was added. The conical flask was kept on mechanical shaker for $24 \mathrm{hrs}$, after that the extract was filtered through Whatman filter paper 1 and the pellet was allowed to drying, and this pellet was used for the next solvent extraction (ethyl acetate and methanol). The dried extracts were recovered and stored in the refrigerator for further analysis.

\section{Quantitative phytochemical analysis}

Estimation of total phenol content

The amount of total phenol was determined using the Folin-Ciocalteu reagent method of Lister and Wilson, 2001 [8]. A standard curve was prepared using gallic acid. Different concentrations of gallic acid were prepared in $80 \%$ methanol, and their absorbance was recorded at $760 \mathrm{~nm} .100 \mu \mathrm{l}$ of sample was dissolved in $500 \mu \mathrm{l}$ of Folin-Ciocalteu reagent (1/10 dilution) and $1 \mathrm{ml}$ of distilled water. The contents were mixed and incubated at room temperature for 1 minute. After 1 minute, $1.5 \mathrm{ml}$ of $20 \%$ sodium carbonate solution was added. The final mixture was shaken well and incubated for $2 \mathrm{hrs}$ in the dark at room temperature. The absorbance of all samples was measured at $760 \mathrm{~nm}$ using an ultraviolet and visible (UV-Vis) spectrophotometer. The results 
were expressed in mg gallic acid equivalents (GAE) per milligram of dry weight of the plant.

\section{Estimation of total flavonoid content}

The flavonoid content in the extract was determined spectrophotometrically by the method of Quettier-Deleu et al., 2000 [9]. This method was based on the formation of a complex, flavonoidaluminum, with the absorbance maximum at $430 \mathrm{~nm}$. Rutin was used as standard to make the calibration curve. $1 \mathrm{ml}$ of diluted sample was separately mixed with $1 \mathrm{ml}$ of $2 \%$ aluminum chloride methanolic solution. After incubation at room temperature for 15 minutes, the absorbance of the reaction mixture was measured at $430 \mathrm{~nm}$ in a UV-vis spectrophotometer. The flavonoid content was expressed in mg per mg of rutin equivalent.

\section{Free radical scavenging ability (DPPH)}

The scavenging ability of methanol extract on DPPH free radicals was estimated according to the method of Shimada et al. (1992) [10]. This method depends on the reduction of purple DPPH to yellow-colored diphenyl picryl hydrazine. $2 \mathrm{ml}$ of various concentrations $(10-100 \mu \mathrm{g} / \mathrm{ml})$ of the test sample was mixed with $0.5 \mathrm{ml}$ of $0.01 \mathrm{M} \mathrm{DPPH}$ in methanol. An equal amount of methanol and DPPH served as a control. The mixture was shaken vigorously and then steadily kept for 30 minutes at room temperature in the dark. The absorbance of the resulting solution was measured at $517 \mathrm{~nm}$ against a blank using UV-vis spectrophotometer. The experiment was performed in triplicates. The DPPH radical scavenging activity was calculated by the following equation:

$\%$ DPPH radical scavenging activity $=\left(A_{0}-A_{1}\right) / A_{0} \times 100 \%$

Where, $\mathrm{A}_{\mathrm{o}}$ is the absorbance of the control reaction and $\mathrm{A}_{1}$ is the absorbance of the sample of the tested extracts. The percentage of free radical activity was plotted against the corresponding antioxidant substance concentration to obtain the half maximal inhibitory concentration $\left(\mathrm{IC}_{50}\right)$ value, which is defined as the amount of antioxidant substance required to scavenge the $50 \%$ of free radicals present in the assay solution. IC $_{50}$ values are inversely proportional to the antioxidant potential.

\section{Reducing power ability}

The reducing power ability of methanol extract was determined by the method given by Oyaizu (1986) [11]. Reaction mixtures were prepared by adding $2.5 \mathrm{ml}$ of phosphate buffer $(0.2 \mathrm{M}, \mathrm{pH} 6.6), 2.5 \mathrm{ml}$ potassium ferricyanide $(0.1 \%)$, and varying concentrations of extracts $(10-250 \mu \mathrm{g} / \mathrm{ml})$. Then, the reaction mixtures were incubated at $50^{\circ} \mathrm{C}$ in water bath for 30 minutes and allowed to cool at room temperature. Then, $2.5 \mathrm{ml}$ of $10 \%$ TCA (trichloroacetic acid) were added to each reaction mixture and centrifuged at $2000 \mathrm{rpm}$ for 10 minutes. The supernatant $(2.5 \mathrm{ml})$ was separated in the test tube and added with $2.5 \mathrm{ml}$ of distilled water and $\left.0.5 \mathrm{ml} \mathrm{FeCl}{ }_{3}, 1.0 \%\right)$. After 10 minutes incubation at room temperature, the absorbance was measured at $700 \mathrm{~nm}$. The ascorbic acid solution was used as standard.

\section{Statistical analysis}

All the data were reported as mean \pm standard deviation of three replicates. The $\mathrm{IC}_{50}$ values were calculated using the $\mathrm{ED}_{50}$ plus $\mathrm{v} 1.0$ programme. Statistical analysis was performed using Microsoft Excel.

\section{RESULTS}

The phenolic compounds may contribute directly to antioxidants activities. The total phenolic content of the extracts was determined as GAE using Folin-Ciocalteu reagent. A calibration curve with different concentration of gallic acid was formed as $\mathrm{y}=0.2976 \mathrm{x}+0.0567$, $\mathrm{R}^{2}=0.9704$ (Fig. 1). According phenol content in methanol extract $0.178 \mathrm{mg} / \mathrm{GAE} \mathrm{mg}$ followed by ethyl acetate extract showed $0.120 \mathrm{mg} / \mathrm{GAE} \mathrm{mg}$ and acetone extract revealed $0.094 \mathrm{mg} / \mathrm{GAE} \mathrm{mg}$.

The total flavonoid content of the extracts was determined as rutin acid equivalent. The calibration curve with different concentration of rutin acid was created as $\mathrm{y}=0.3351 \mathrm{x}-0.1085 ; \mathrm{R}^{2}=0.9905$ (Fig. 2). Methanol extract showed a significant amount of flavonoid content $0.225 \mathrm{mg} / \mathrm{mg}$ RAE followed by ethyl acetate extract revealed $0.155 \mathrm{mg} / \mathrm{RAE} \mathrm{mg}$ and acetone extract possess $0.136 \mathrm{mg} / \mathrm{RAE} \mathrm{mg}$.

In this study, percentage of inhibition of different extracts were calculated and compared with ascorbic acid as a standard. Methanol extract shows a higher percentage of inhibition (64.39\%) than other solvent extract ethyl acetate revealed (58.21\%) and acetone extract possesses (49.40\%). All the extracts have lower $\%$ of inhibition compare with ascorbic acid (91.94\%) (Fig. 3).

Fig. 4 showed the reducing ability of ascorbic acid as a standard. Different solvent extracts of $P$. umbellatum leaves of reducing power compared to ascorbic acid. Among the tested solvent, methanol extract exhibited higher reducing activity $(0.435 \mathrm{mg} / \mathrm{AA} \mathrm{mg})$ followed by ethyl acetate extract shows $0.341 \mathrm{mg} / \mathrm{AA} \mathrm{mg}$ and acetone extract revealed $(0.308 \mathrm{mg} / \mathrm{AA} \mathrm{mg})$.

\section{DISCUSSION}

Flavonoids are a group of polyphenolic compounds known properties which include free radical scavenging and inhibition of hydrolytic and oxidative enzymes and inflammatory activity [12]. In this study, the quantitative analysis of phenol and flavonoid content of the extracts highly correlated to the previous results [13]. The previous reports of P. umbellatum revealed steroid, flavonoid, tannin, alkaloid, saponin, and phenol in the leaves extract [14]. The activity of free radical scavenging activity of the plant extracts at different concentrations increases with increasing concentrations. Similar observation was made in the methanolic extract of Piper longum [15]. The results showed that the antioxidant activity was higher for methanol extract of $P$. umbellatum as followed by ethyl acetate and acetone extracts. DPPH is a nitrogen-

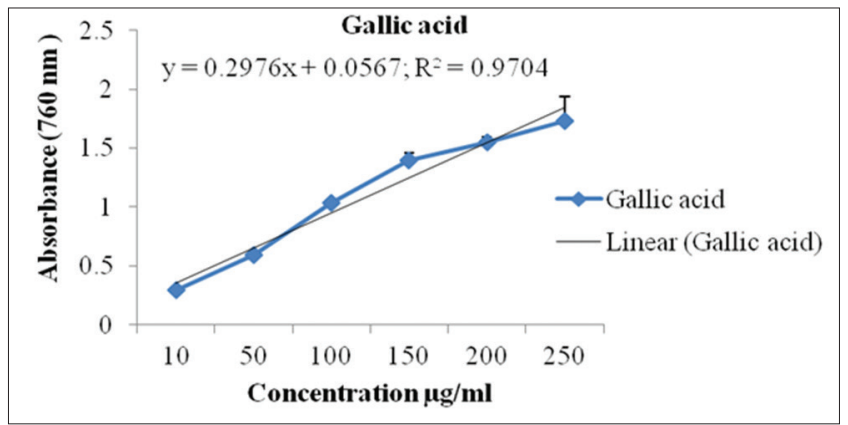

Fig. 1: Standard curve of gallic acid for total phenol estimation. All values are reported as mean $\pm S D(n=3)$. SD: Standard deviation

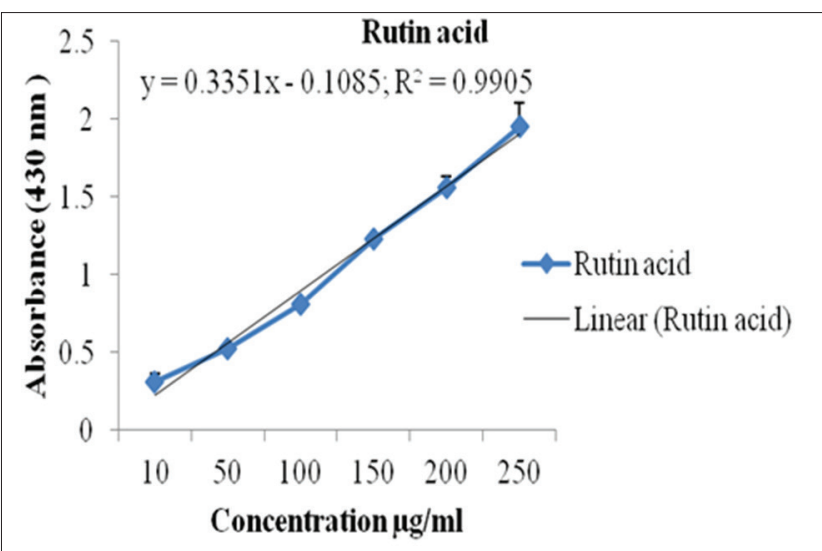

Fig. 2: Standard curve of rutin for total flavonoid estimation. All values are reported as mean $\pm S D(n=3)$. SD: Standard deviation 


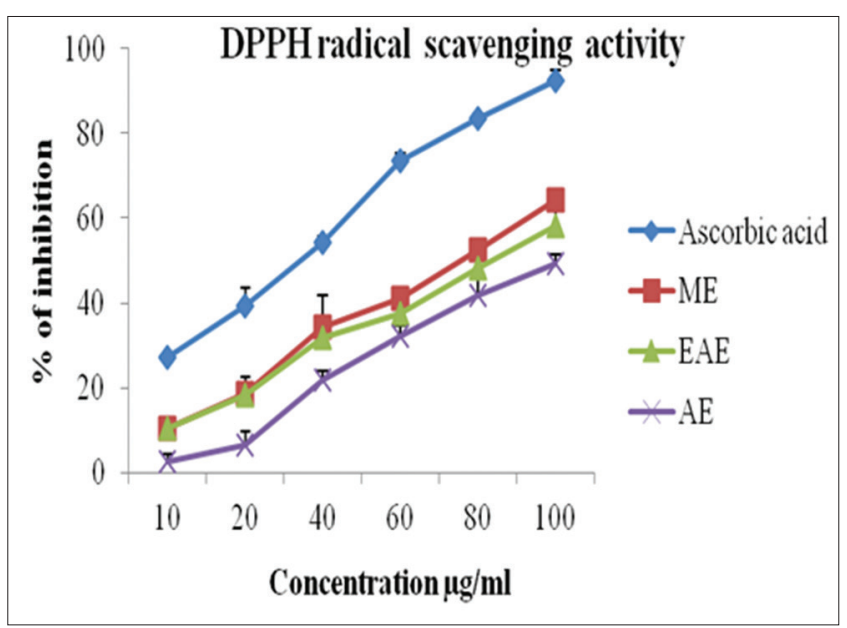

Fig. 3: Percentage inhibition of 1, 1-diphenyl-2-picrylhydrazyl by ascorbic acid and different solvent extracts of Piper umbellatum. ME: Methanol Extracts, EAE: Ethyl Acetate Extract, AE: Acetone Extract. All values are reported as mean \pm Standard deviation $(n=3)$

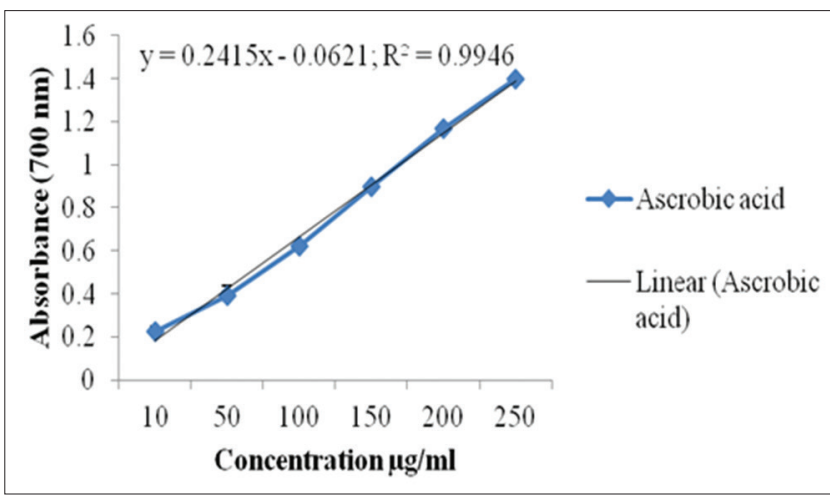

Fig. 4: Reducing power capacity of ascorbic acid. All values are reported as mean $\pm S D(n=3)$. SD: Standard deviation

centered free radical molecules [16]. The previous researcher reported on extract react with a free radical molecule (single electron - DPPH) after reaction free radical convert to nonfree radical when tested extract give one electron changes to pair electron $(\mathrm{DPPH}+\mathrm{H})$ and the presence of phenol and flavonoid content in tested extracts. Before testing, the DPPH dark brown color after dilution with ethanol changes to deep violet color. Deep violet color DPPH solution tested the different concentration of extract and the color changes to yellow. During the reaction, violet color solution suddenly changes to yellow color because the tested extract found a high amount of antioxidant properties $[17,18]$. Reducing power was measured the reductive ability of antioxidant, and transformation of $\mathrm{Fe}^{+3}$ to $\mathrm{Fe}^{+2}$ in the presence of the extract [19]. Increasing reducing power was increased when the concentration increased. A higher absorbance indicates a higher reducing power. In earlier researcher reported, the similar antioxidant activity possesses in the methanolic extract Baccaurea courtallensis [20]. Several reports indicated the phenolic content of the plant extracts had the reducing power of bioactive compounds and associated with antioxidant activity [21]. Our results revealed that the leaves of different solvent extracts of $P$. umbellatum showed same scavenging activity compared with in earlier report [22].

\section{CONCLUSION}

In this study, indicated the three extracts of $P$. umbellatum have potent antioxidant capacity in DPPH and ferric reducing antioxidant power assay methods. Thus, it can be concluded that considered good sources of natural antioxidants substances to health systems.

\section{ACKNOWLEDGMENT}

The corresponding author is grateful to University Grants Commission, New Delhi for providing financial assistance under Research Award Scheme.

\section{REFERENCES}

1. Halliwell B. Free radicals, antioxidants, and human disease: Curiosity, cause, or consequence? Lancet 1994;344(8924):721-4.

2. Kühnau J. The flavonoids. A class of semi-essential food components: Their role in human nutrition. World Rev Nutr Diet 1976;24:117-91

3. Younes M, Siegers CP. Inhibitory action of some flavonoids on enhanced spontaneous lipid peroxidation following glutathione depletion. Planta Med 1981;43(3):240-4.

4. Halliwell B Gutteridge JM. Oxygen toxicity, oxygen radicals, transition metals and diseases. Biochem J 1984;219:1-4.

5. Nunez V, Castro V, Nurillo R, Ponce-soto, LA, Merfoot I, Lomonte B. Inhibitory effects of Piper umbellatum and Piper peltatum extracts towards myotoxic phospholipase A2 from Bothrops snake venoms: Isolation of 4-nerolidylcatchol as active principle. Phytochemistry 2005;66:1017-25.

6. Dyer LA, Palmer AN. Piper: A Model Genus for Studies of Evolution, Clinical Ecology and Trophic Interactions. Boston: Kluwer Academic Publishers; 2004.

7. Ahmad FB, Cheksum T. Phytochemical studies on Piper umbellatum L. Asean Rev Biodivers Environ Conserv 2002;8:1-4

8. Lister E, Wilson P. Measurement of Total Phenolics and ABTS Assay for Antioxidant Activity (Personal Communication). New Zealand: Crop Research Institute, Lincoln; 2001.

9. Quettier-Deleu C, Gressier B, Vasseur J, Dine T, Brunet C, Luyckx M, et al. Phenolic compounds and antioxidant activities of buckwheat (Fagopyrum esculentum Moench) hulls and flour. J Ethnopharmacol 2000;72(1-2):35-42.

10. Shimada K, Fujikawa K, Yahara K, Nakamura T. Antioxidative properties of xanthan on the autoxidation of soybean oil in cyclodextrin emulsion. J Agric Food Chem 1992;40:945-8.

11. Oyaizu M. Studies on products of browning reactions: Antioxidant activities of products of browning reaction prepared from glucose amine. Jpn J Nutr 1986:44:307-15.

12. Gryglewski RJ, Korbut R, Robak J. On the mechanism of antithrombotic action of flavonoids. Biochem Pharmacol 1987;36:317-21.

13. Suja S, Mohanasundari L. Antioxidant and free radical scavenging activity of the mixture of ethanolic extracts of Alpinia speciosa and Alpinia calcarata rhizome. Int J Pharm Pharm Sci 2016;8(8):164-70.

14. Nwauzoma AB, Songo LD. Study on the phytochemical properties and proximate analysis of Piper umbellatum (Linn) from Nigeria. Am J Res Commun 2013;1(7):164-77.

15. Santhy KS, Archana D, Dixitha M. Antioxidant and anti Clastogenic potential of Piper longum L. Int J App Pharm 2015;7(2):11-4.

16. Yamaguchi T, Takamura H, Matoba T, Terao J. HPLC method for evaluation of the free radical scavenging activity of foods by using 1, 1-diphenyl-2-picrylhydrazyl. Biosci Biotech Biochem 1998;62:1201-4.

17. Tripathi YB, Chaurasia S, Tripathi E, Upadhyay A, Dubey GP. Bacopa monniera Linn. as an antioxidant: Mechanism of action. Indian J Exp Biol 1996;34:523-6.

18. Irulandi $\mathrm{K}$, Geetha $\mathrm{S}$, Mehalingam P. Evaluation of antioxidant properties and antimicrobial activity of Garcinia cambogia Hort. Ex Boerl (Clusiaceae) fruit extracts. J Adv Appl Sci 2016;1(3):74-83.

19. Gulcin I, Oktay M, Kirecci E, Kufrevio I. Screening of antioxidant and antimicrobial activities of anise (Pimpella anisum L.) seed extracts. Food Chem 2003;83:371-82.

20. Irulandi K, Mehalingam P. In vitro antioxidant and antimicrobial properties of Baccaurea courtallensis (Wight) Mull.-Arg. (Euphorbiaceae) fruit extracts. J Outreach 2015:7;64-75.

21. Siddhuraju P Mohan PS, Becker K. Studies on the antioxidant activity of Indian Laburnum (Cassia fistula L.): A preliminary assessment of crude extracts from stem bark, leaves. Flowers and fruit pulp. Food Chem 2002;79:61-70.

22. Agbor GA, Vinson JA, Oben JE, Ngogang JY. In vitro antioxidant activity of three Piper species. J Herb Pharmacother 2007;7(2):49-64. 